\title{
G som \\ Experimental Analysis of Pore Structure and Fractal Characteristics of Soft and Hard Coals With Same Coalification
}

\section{Barkat Ullah}

China University of Mining and Technology - Xuzhou Campus: China University of Mining and Technology https://orcid.org/0000-0002-8342-8381

Yuanping Cheng ( $\square$ ypcheng@cumt.edu.cn )

China University of Mining and Technology - Xuzhou Campus: China University of Mining and Technology

\section{Liang Wang}

China University of Mining and Technology - Xuzhou Campus: China University of Mining and Technology

\section{Weihua Yang}

China University of Mining and Technology - Xuzhou Campus: China University of Mining and Technology

\section{Izhar Mithal Jiskani}

China University of Mining Technology: China University of Mining and Technology

\section{Biao Hu}

China University of Mining and Technology - Xuzhou Campus: China University of Mining and Technology

\section{Research}

Keywords: methane adsorption, soft and hard coal, pore structure, fractal pore characteristics, N2/CO2 adsorption

Posted Date: August 31st, 2021

DOl: https://doi.org/10.21203/rs.3.rs-824436/v1

License: (c) (i) This work is licensed under a Creative Commons Attribution 4.0 International License. Read Full License 


\section{Abstract}

Accurate and quantitative investigation of the physical structure and fractal geometry of coal has important theoretical and practical significance for coal bed methane and the prevention of dynamic disasters such as coal and gas outbursts. This study investigates the pore structure and fractural characteristics of soft and hard coals using nitrogen and carbon dioxide $\left(\mathrm{N}_{2} / \mathrm{CO}_{2}\right)$ adsorption. Coal samples from Pingdingshan Mine in Henan province of China were collected and pulverized to the required size (0.2-0.25mm). $\mathrm{N}_{2} / \mathrm{CO}_{2}$ adsorption tests were performed to evaluate the pore size distribution (PSD), specific surface area (SSA), and pore volume (PV). The pore structure was characterized based on fractural theory. The results unveiled that the strength of coal has a significant influence on pore structure and fracture dimensions. The obvious $\mathrm{N}_{2}$-adsorption isotherms of the coals were verified as Type IV (A) and Type II. The shape of the hysteresis loops indicates the presence of slit-shaped pores. There are significant differences in SSA and PV between both coals. The soft coal showed larger SSA and PV than hard coal that shows consistency with adsorption capacity. The fractal dimensions of soft coal are respectively larger than that of hard coal. The greater the value of $D_{1}$ (complexity of pore surface) of soft coal is, the larger the pore surface roughness and gas adsorption capacity is. The results enable us to conclude that the characterization of pores and fractures of soft and hard coals is different, tending to different adsorption/desorption characteristics and outburst sensitivity. In this regard, results provide a reference for formulating corresponding coal and gas outburst prevention and control measures.

\section{Introduction}

Coal and gas outburst is a complex dynamic phenomenon associated with coal, rock, and gas in coal mines, which is one of the most serious natural disasters in the process of coal mining (Li et al., 2017; C. Wang et al., 2017; Yue et al., 2019a, 2019b). Coalbed methane is considered a driving force of coal and gas outbursts. It occurs in multilayer deposition in coal seam; adsorbed on the pore surface of coal, as a part of coal molecular structure, in cracks and large pores, the adsorbed gas controls the occurrence of coal and gas outburst (Sun et al., 2020; Zarebska and Ceglarska-Stefańska, 2008). It is generally believed that coal and gas outbursts result from gas pressure, in-situ stress, and the mechanical properties of coal. Gas pressure and in-situ stress are positively correlated with coal and outburst strength. In contrast, coal's mechanical properties are negatively correlated with the intensity of coal and gas outbursts (Chen, 2011; L. Wang et al., 2017; Wang et al., 2013; Xue et al., 2014). Coal with different destruction degrees is formed by tectonic movement is often called tectonic coal that is considered an essential condition for coal and gas outbursts. Many researches revealed it as an abundant factor in coal and gas outbursts (Yue et al., 2019b). In addition, coal with different damage degrees has different pore structures and adsorption properties. Therefore, it is worth investigating the pore structure characteristics and adsorption characteristics of tectonic coals to enhance coalbed methane recovery and prevent coal and gas outbursts (Yue et al., 2019b). 
The original structure of coal or slightly damaged coal is designated as hard coal, while seriously damaged coal is specified as soft coal in the production practice (Tang et al., 2005). Coal with a hardness coefficient $(f)$ more than 0.5 is called hard coal, and coal with a hardness coefficient less than 0.5 is called soft coal. Studies show that the metamorphic degree of soft coal is slightly higher than that of hard coal (Sun et al., 2020; Yue et al., 2019b). However, hard coal and soft coal's adsorption and desorption characteristics are pointedly different in actual production. If the research is not differentiated, it will lead to inaccurate prediction and inadequate performance tests. In addition, many mines have a certain thickness of soft stratification in the coal seam. The hardness coefficient $(f)$ is the main index used to differentiate these coals and is considered the main indicator for the classification of coal seams in the degree of a significant hazard (Sun et al., 2020).

The soft coal shows dynamic phenomenon or outburst risk because of its poor permeability, low strength, rapid gas desorption speed, and high gas content. The pore structure connectivity is influenced by the strength of coal, which may lead to a difference in adsorption/desorption properties. The seam thickness of soft coal (varies from several centimeters to the height of the whole bed) changes significantly, and most of them are unstable. Thus, investigating pore and fracture structure characteristics is vital to understand the adsorption/desorption phenomenon (Cheng et al., 2011; Wei et al., 2019). In general, coal is considered an organic rock consisting of pores and fractures, which act as a gas reservoir and migration channels for methane and other gases (Ren et al., 2019a; Shi and Durucan, 2005, 2003). Methane is the main component of Coalbed Methane (CBM) occurrence, which is adsorbed on the matrix of coal surface. During the development of CBM, the fracture system is often saturated with formation water, providing an effective channel for gas-water migration (Yao et al., 2010). The behavior of gas adsorption, flow and transport is affected by pore morphology (i.e. coal seam pore system), which is the key to understand the adsorption /desorption mechanism in the long-term storage process (C.R. Clarkson and Bustin, 1999). Generally, pore morphology includes pore volume (PV), specific surface area (SSA), pore size distribution (PSD), pore shape, connectivity, and fractal dimension (Zhang et al., 2013). Based on the complexity of coal pore structure, including the universality of PSD, diversity of pore geometry, and network structure, coal pores are classified into different types that have different effects on gas adsorption and seepage in the coal matrix (Yin et al., 2018). The latest and widely used pore classification standard defined by the International Union of Pure and Applied Chemistry (IUPAC) classifies pores are macropore $(>50 \mathrm{~nm})$, mesopore $(2.00-50.00 \mathrm{~nm})$, and micropore $(<2.00 \mathrm{~nm})$, while micropore is divided into ultra-micropore $(<0.70 \mathrm{~nm})$ and super-micropore $(0.70-2.00 \mathrm{~nm})$ ( Li et al., 2014; Thommes et al., 2015; Wu and Wang, 2013; Yao et al., 2009a). Coal pores are also divided into seepage pores $(>100 \mathrm{~nm})$ and adsorption pores $(<100 \mathrm{~nm})$. The pores smaller than $100 \mathrm{~nm}$ are usually defined as nanopores (Barsotti et al., 2016b; Fu et al., 2017a; Ren et al., 2019a; Zhang et al., 2017). Various methodologies have been developed and used to evaluate the PSD and porosity of the porous materials. These methods can be categorized into liquid invasion method and radiation method (Clarkson et al., 2013; Y. Zhao et al., 2014). Fluid intrusion methods include high pressure mercury intrusion (MICP) and low pressure adsorption (LPA), using $\mathrm{N}_{2}$ and $\mathrm{CO}_{2}$. Radiation methods contain optical microscope, scanning electron microscope (SEM), transmission electron microscope (TEM), synchrotron small angle 
X-ray scattering (SAXS), small angle neutron scattering (SANS), nuclear magnetic resonance (NMR), and X-ray micro-computed tomography (micro CT) (Y. Zhao et al., 2014).

In this study, the pore structure and fractural characteristics of hard and soft coals are investigated, which provides a reference for CBM development and prevention of dynamic disasters like coal and gas outbursts. The research was undertaken on samples collected from the Pingdingshan No. 6 coal mine, China. The studied mine has a high gas content and pressure in coal seams, which are the key factors causing frequent outbursts. Regarding the outburst occurrence sensitivity of the coal mine, the Ding seam (soft coal) is more sensitive, and its gas content and gas pressure are comparatively higher than that of the Wu seam (hard coal) (Barkat Ullah et al.,2021). In this research, both the Ding and Wu coals were investigated with different destruction degrees. The coalification test was performed, and the coal seams are designated as low volatile bituminous coal (see Sect. 3.1). To understand the sensitivity variation in coal and gas outburst of coal seams with the same coalification and different destruction degree, a couple of tests ( $\mathrm{N}_{2} / \mathrm{CO}_{2}$ adsorption) were performed to evaluate the PSD, SSA, and PV of micropores and mesopores.

\section{Material And Methods}

Coal samples were collected from two coal seams (Ding 5-6 and Wu 9-10) of Pingdingshan No. 6 Coal Mine in Henan province, China. The samples were pulverized to the required size $(0.2-0.25 \mathrm{~mm})$ prior to $\mathrm{N}_{2} / \mathrm{CO}_{2}$ adsorption and $\mathrm{CH}_{4}$ adsorption tests. The samples were dried at $50^{\circ} \mathrm{C}$ for at least 48 hours. The samples from the Ding seam were labeled as DN56-1 and DN56-2, and those from Wu coal seams were named as WU910-1 and WU910-2, respectively. The samples were wrapped in an isolated container to avoid the influence of external moisture and brought to the laboratory to determine the physical parameters listed in Table1. The strength coefficient of coal samples was determined by a drop weight method. The values of vitrinite reflectance were determined by a theoretical approach based on the volatile content of coal. Cheng's equation (Eq. 1) was used to determine the values of vitrinite reflectance $\left(R_{0}\right)$ (Cheng et al., 2017).

$$
V_{\text {daf }}=29.63 R_{0}^{-1.05}
$$

where $V_{\text {daf }}$ is the volatile content and $R_{0}$ is the vitrinite reflectance.

The mesoporous/micropores morphology was characterized by the physical adsorption method $\left(\mathrm{N}_{2}\right.$ and $\mathrm{CO}_{2}$ as probe molecules) with an automatic Autosorb IQ2 gas adsorption analyzer (Quantachrome instrument, manufactured in USA), as shown in Fig. 1. For $\mathrm{N}_{2}$ adsorption at $77 \mathrm{~K}$, the measurement range of mesopore is 2-50nm, and the $\mathrm{N}_{2}$ adsorption isotherms can give better results at a relative pressure $\left(\mathrm{P} / \mathrm{P}_{0}\right)$ from 0.001 to 0.995 . In the analysis of microspores morphology, $\mathrm{CO}_{2}$ adsorption at $273 \mathrm{k}$ can overcome the shortcoming of $\mathrm{N}_{2}$ adsorption to determine micropores smaller than $2 \mathrm{~nm}$. Due to the smaller molecular dynamics diameter and shorter adsorption equilibrium time, it is more accurate to 
obtain a small pore size in the microporous area, especially in the range of 0.35-1.5nm (C.R. Clarkson and Bustin, 1999).

The adsorption isotherms obtained from $\mathrm{N}_{2}$ adsorption (at 77K) were analyzed by Braunuer-EmmettTeller (BET), Barrett-Joyner-Halenda (BJH), and Density Functional Theory (DFT) methods to obtain the PSDs, PV, and SSA. However, based on BJH model, the PSD, PV, and SSA of mesopores and a small number of macropores can be calculated, while DFT model is favorable to determine PSD, PV, and SSA of mesopores and low range of partial micropores. Therefore, BJH model was considered better for accurate determination of PSD, PV, and SSA of mesopores. On the other hand, BET model is widely used to obtain SSA of mesopores (Jiang et al., 2019a; Sun et al., 2015; Wang et al., 2019).

For micropores characterization, $\mathrm{CO}_{2}$ adsorption isotherms (at 273K) were obtained. Later these isotherms were analyzed by Quenched Solid Density Functional Theory (QSDFT) to obtain PV and SSA of micropores. Frenkel-Halsey-Hill $(\mathrm{FHH})$ model is the most effective method to calculate the fractal dimension of coal adsorption pore based on gas adsorption isotherm (Fu et al., 2017b; Jiang et al., 2019b; Wang et al., 2018). Therefore, the fracture features of coal samples were determined by the FHH model expressed in Eq. 2.

$$
\ln \left(\frac{\mathrm{V}}{\mathrm{V}_{\mathrm{o}}}\right)=\mathrm{A}+\left(\mathrm{D}_{\mathrm{n}}-3\right) \ln \left[\left(\frac{\mathrm{P}_{\mathrm{o}}}{\mathrm{p}}\right)\right]
$$

where $\mathrm{V}$ and $\mathrm{V}_{0}$ represent the adsorption volume and the monolayer absorption volume, respectively; $\mathrm{V} / \mathrm{V}_{0}$ is the relative adsorption volume; $\mathrm{P}_{0}$ and $\mathrm{P}$ are the saturated vapor pressure and equilibrium pressure of the gas, respectively; $\mathrm{A}$ is a constant value.

\section{Results And Discussion 3.1 Proximate analysis}

The proximate analysis results, density (true and false), and porosity of coal samples are shown in Table 1. The values of physical parameters are consistent. While the firmness coefficient $(f)$ values of coal particles are $0.16,0.18,0.71$, and 0.67 , respectively, which reveals that the Wu seam has high strength than Ding. Whereas the values of vitrinite reflectance fall in the range of $(0.5 \%<$ Ro; $\max >0.9 \%)$, designate coalification of Ding and Wu seams as low volatile bituminous coal, according to (Cheng et al., 2017).

\section{$3.2 \mathrm{~N}_{2}$ Adsorption Isotherms}

Figure 2 shows the adsorption isotherms of coal samples DN56-1, DN56-2, WU910-1, and WU910-2, respectively. According to the IUPAC classifications of isotherms, the adsorption isotherms obtained from low temperature $\mathrm{N}_{2}$-adsorption experiments are classified as type IV (A) and type II. The shape of this kind of adsorption branch of the hysteresis loop is caused by the adsorption of a monolayer on the 
surface. Then, multilayer and capillary condensation of gas molecules occur (Thommes et al., 2015; Wei et al., 2019). The significant rise of adsorption isotherms at low pressure $\left(P / P_{0}\right)$ region corresponds to microspores filling, while at the beginning of isotherm, indicating the completion of monolayer adsorption and starting of multilayer adsorption (Jin et al., 2016; Thommes et al., 2015).

Capillary condensation occurs in mesopores with pore size larger than a certain critical size, which is mainly caused by adsorption metastable and/or pore network effect, and width of adsorption hysteresis loop increases with the increase of pore size (Barsotti et al., 2016b; Nie et al., 2015). With a gradual increase of relative pressure $P / P_{0}$, the rise in the curve happens again, which results in capillary condensation during mesopores adsorption (Barsotti et al., 2016a; Jiang et al., 2019a). The presence of the hysteresis loop indicates that the evaporation in the pore is significantly different from the condensation in the pore and that capillary condensation occurs under mesopores (C. R. Clarkson and Bustin, 1999; Wang et al., 2019).

The desorption branch of the isotherm of coal depends on the influence of the pore network and various forms of pore blockage, thus reflecting the network structure characteristics of the pores (Jiang et al., 2019a). From Fig. 2 , it can be seen that at high relative pressure $P / P_{0}=0.98-0.99$, the desorption branch decreases sharply and coincides with the adsorption branch at the equilibrium desorption zone. With the decrease of relative pressure $\left(P / P_{0}=0.5\right)$, the adsorption and desorption branches detach from each other, which indicates evaporation and desorption of condensed phase in pores. Finally, at the extremely lower pressure phase, the desorption branch drops, showing the detachment of monolayers adsorbed molecules. Figure 3. shows the shape of pores corresponding to hysteresis loops, the adsorption/desorption isotherm of coal samples from Ding and Wu belongs to type $B$, indicating the presence of numerous slit-shaped pores. Adsorption/ desorption branches at low pressure regions did not depart from each other, giving no evidence of cylindrical type pores (Nie et al., 2015). The width of adsorption isotherms explains the PSD and pores shape. Adsorption isotherms obtained in this study are obvious, which indicate the micro-mesoporous nature of coal.

\subsection{Pore Size Distribution, Pore Volume, and Specific Surface determined by $\mathrm{N}_{2}$-Adsorption}

Various studies confirmed that PV and SSA of mesopores by $\mathrm{N}_{2}$-Adsorption test could be quantitatively determined by BET and BJH models (Yao et al., 2009b). The results of PSDs, PV, and SSA from low temperature $\mathrm{N}_{2}$-adsorption experiment were obtained with the help of ASiQwin software from Quantachrome (United States). Figure 4 explains PSD results determined by the BJH and DFT model based on the $\mathrm{N}_{2}$-adsorption experiment. PSD results show multimodal mode. According to BJH result of PSDs, DN56-1 contains microspores and fewer amount of mesopores. The PSD of DN56-1 ranges from 0.9-4nm. While DN56-2 exhibits PSD of mesopores and a small number of macropores, ranging from 29nm. Coal samples WU910-1 and WU910-2 are dominated by mesopores. The pore size distributions of WU910-1 and WU910-2 are concentrated around 2-8nm. More precisely, the coal samples from Ding coal 
seam are more dominant in quantity by mesopores and micropores, evidenced by pore size distributions, BET SSA, and BJH PV (see Table 2).

Table 2

PSDs, Pore Volume and SSA obtained by $\mathrm{N}_{2}$-adsorption Test.

\begin{tabular}{|lllll|}
\hline \multicolumn{2}{|c}{ Coal sample } & BJH Pore size $(\mathrm{nm})$ & BJH Pore volume $\left(\mathrm{cm}^{3} / \mathbf{g}\right)$ & BET $\left(\mathrm{m}^{2} / \mathbf{g}\right)$ \\
\hline \multirow{2}{*}{ Soft coal } & DN56-1 & 0.747 & 0.029 & 3.523 \\
\cline { 2 - 5 } & DN56-2 & 2.922 & 0.032 & 4.783 \\
\multirow{2}{*}{ Hard coal } & WU910-1 & 3.568 & 0.024 & 2.941 \\
\cline { 2 - 5 } & WU910-2 & 2.522 & 0.014 & 2.819 \\
\hline
\end{tabular}

$\mathrm{N}_{2}$ adsorption using DFT (DFT- $\mathrm{N}_{2}$ ) primarily shows the lower pore size range of mesopores and low range of partial micropores (<30 nm) (Zhang et al., 2017). In Fig. 4 the PSD of mesopores and partial micropores obtained by DFT is presented. It can be seen that coal samples DN56-1, DN56-2, and WU9102 are dominated by mesopores, and a reasonable concentration of micropores $(<2 n m)$ is observed, while WU910-1 exhibits mesoporous concentration. According to the DFT model, the PSDs ranges of DN56-1, DN56-2, WU910-2, and WU910-2 are 2-9nm, 1-10nm, 4-9nm, and 2-8nm, respectively.

The SSA of the sample was determined by BET method, and the results are displaced in Fig. 5. For Ding seam (soft coal), the SSA increases with the increase of destruction type. The reason is that the SSA is closely related to the microporous structure of coal. The structural responses of destruction types of coal under periodic and anisotropic tectonic stress are different. The contact area of coal samples with low damage degrees can be increased by displacement, rotation, and rearrangement of coal skeleton particles. The internal stress of coal skeleton particles is balanced again. With the increase of the damage degree, the development of multiple groups of fractures gradually disappears in the macrospore's phase, and many nanopores are formed in the microspore's aspect. Tectonic stress produces strong crushing and pulverization, which strongly influences mesopores and especially micropores evolution, which is evident by a study (Yue et al., 2019b). This also indicates that pulverized intact coal does indeed affect the coal's pore structure. An increase in PV and BET-SSA may be related to new pores that appear during the crushing/pulverization process (Hou et al., 2017). The SSAs of coal samples DN56-1 and DN56-2 (soft coals) are greater than WU910-1 and WU910-2 (hard coal). The result implies that Ding seam has high adsorption capacity than Wu. Table 2 shows PSD, PV, and SSA obtained by BJH and BET models. PSDs, TVP, and BET-SSA determined by $\mathrm{N}_{2}$-adsorption, ranges from 0.7-3.5nm, $0.01-0.03 \mathrm{~cm}^{3} / \mathrm{g}$, and $2.8-4.7 \mathrm{~m}^{2} / \mathrm{g}$, respectively.

\subsection{Analysis of Micropores by $\mathrm{CO}_{2}$-Adsorption}

Micropore analysis can be conducted under nitrogen adsorption at 77K. However, due to the slow diffusion and large molecular diameter of nitrogen at $77 \mathrm{~K}$, this method is not ideal in the quantitative 
evaluation of micro-porosity, especially in the range of ultra-micropores (pore diameter $<0.7 \mathrm{~nm}$ ) (Jin et al., 2016). In addition, due to the larger specific interaction of $\mathrm{CO}_{2}$ than $\mathrm{N}_{2}$, the volume and SSA of coal microspores measured with these two gases are quite different. The SSAs of coal measured by $\mathrm{CO}_{2}$ adsorption can give a value of several hundred square meters per gram (Amarasekera, G.; Scarlett, M. J.; Mainwaring, 1995; Jin et al., 2016) .

Figure 6 shows the $\mathrm{CO}_{2}$-adsorption isotherms, showing that the adsorption quantity increases gradually with increasing relative pressure. Comparing coal samples DN56-1, DN56-2, WU910-1, and WU910-2, $\mathrm{CO}_{2}{ }^{-}$ adsorption isotherms showed dramatic changes. The adsorption curve of the DN56-1 coal sample shows an increasing trend in the low-pressure region, and the DN56-1 curve is lagged by WU910-1 in the highpressure region. The exact change can be seen between DN56-2 and WU910-2 curves.

Micropore is an important index to evaluate the enrichment and adsorption capacity of coalbed methane. However, at present, the super micropores with a diameter less than $2 \mathrm{~nm}$ have not apprehensive enough attention. The characteristics of super micropores have a decisive impact on the adsorption performance of methane (Chen et al., 2017; Zhao et al., 2016). QSDFT considers the heterogeneity of materials, which is highly effective in the analysis of pore size of micro-mesoporous materials (Neimark, A. V.; Lin, Y.; Ravikovitch, P. I.; Thommes, 2009). Based on $\mathrm{CO}_{2}$ adsorption experiment, PSD, PV, and SSA of Ding and Wu coal seams are determined. $\mathrm{CO}_{2}$ Isotherms analyzed by AsiQwin software and QSDFT model give a favorable approach to obtain PSDs, TPV, and SSA of micropores (super and ultra-micropores). QSDFT model is also favorable to determine the PSD of the micropores with pore size in the range of $0.35-1.50$ $\mathrm{nm}$, as depicted in Fig. 7 (Jiang et al., 2019a). PSDs of coal samples are mainly concentrated by ultramicropores, and a notable amount of super-micropores is also revealed. The obtained PSD peaks have multimodal mode, and all of them are located between $0.3-0.7$ and $0.75-0.9 \mathrm{~nm}$. Among the four samples taken, the PSDs peak in the region of ultra-micropores, especially in the range of $0.3-0.4 \mathrm{~nm}$, the peaks of samples taken from Ding seam are higher than Wu seam. It can be evident that the Ding coal seam is enriched by ultra-micropores, and the adsorption quantity is attributed maximum in the ultra-microporous region. PSDs, TPV, and SSA of DN56-1, DN56-2, WU910-1, and WU910-2 are displayed in Table 3, ranging from $0.36-0.58 \mathrm{~nm}, 0.033-0.039 \mathrm{~cm}^{3} / \mathrm{g}$, and $101.01-111.87 \mathrm{~m}^{2} / \mathrm{g}$, respectively. It can be noticed that the SSA of micropores of soft coal is greater than hard coal, which is attributed to the high adsorption capacity of soft coal. 
Table 3

Pore size distribution, pore volume, and SSA obtained by $\mathrm{CO}_{2}$-adsorption test.

\begin{tabular}{|c|c|c|c|c|c|c|c|c|}
\hline \multicolumn{2}{|c|}{ Coal sample } & \multirow{2}{*}{$\begin{array}{l}\text { DFT } \\
\text { Micropores } \\
\text { size } \\
(\mathrm{nm})\end{array}$} & \multirow{2}{*}{$\begin{array}{l}\text { DFT Micropore } \\
\text { volume } \\
\mathrm{cm}^{3} / \mathrm{g}\end{array}$} & \multirow{2}{*}{$\begin{array}{l}\text { DFT } \\
\text { Micropore } \\
\text { SSA } \\
\mathrm{m}^{2} / \mathrm{g}\end{array}$} & \multicolumn{4}{|c|}{ Fractal dimensions } \\
\hline & & & & & $\mathrm{D}_{1}$ & $\mathrm{R}^{2}$ & $\mathrm{D}_{2}$ & $\mathrm{R}^{2}$ \\
\hline \multirow{2}{*}{$\begin{array}{l}\text { Soft } \\
\text { coal }\end{array}$} & DN56-1 & 0.548 & 0.037 & 106.016 & 2.59 & 0.99 & 2.37 & 0.99 \\
\hline & DN56-2 & 0.573 & 0.039 & 111.872 & 2.62 & 0.99 & 2.20 & 0.98 \\
\hline \multirow[t]{2}{*}{$\begin{array}{l}\text { Hard } \\
\text { coal }\end{array}$} & $\begin{array}{l}\text { WU910- } \\
1\end{array}$ & 0.479 & 0.035 & 103.822 & 2.56 & 0.99 & 2.39 & 0.98 \\
\hline & $\begin{array}{l}\text { WU910- } \\
2\end{array}$ & 0.365 & 0.033 & 101.181 & 2.47 & 0.98 & 2.39 & 0.99 \\
\hline
\end{tabular}

Fractal dimension is widely used to describe the anisotropy and complexity of pore structure. For coal, fractal features represent the complexity of pores and the roughness of the pore surface, which can be determined by $\mathrm{N}_{2}$ (77K) adsorption data. The $\mathrm{FHH}$ model has been verified to be the most efficacious method to obtain fractal dimensions. Many studies showed that the dividing point of FHH fractal curve " $\left(P_{0} / P\right)=-0.5$ " (corresponding aperture about $5 \mathrm{~nm}$ ) divides the curve into two stages: $D_{1}$ and $D_{2}$. Generally, $D_{1}$ and $D_{2}$ are used to characterize the complexity of pore surface and pore structure, respectively (Wang et al., 2018).

FHH fractal results, shown in Fig. 8, indicate an obvious segmentation, and both intervals have a different outcome, which resembles previous works. The fractal dimensions $D_{1}\left(P_{0} / P<0.5\right)$ and $D_{2}\left(P_{0} / P>0.5\right)$ are estimated by an expression $D=3+A$, and all values are lying between 2 and 3 , which yield to the fractal dimensions range (Fu et al., 2017b; Yao et al., 2008).

Previous studies illustrate that $D_{1}$ and $D_{2}$ represent surface fractal dimensions and pore structure complexity, respectively (Fu et al., 2017b; Wang et al., 2018; Yao et al., 2008). The higher the value of $D_{1}$, the rougher the surface, corresponding to more adsorption sites and higher adsorption capacity of gas in coal. On the contrary, the higher the $\mathrm{D}_{2}$, the more complex pore structure of coal, indicating more vigorous capillary condensation and lower methane adsorption capacity of gas in (Ren et al., 2019b; Yao et al., 2008). The values of $D_{1}$ and $D_{2}$ for samples are displaced in Fig. 9 and Table 3 . It can be noticed that the value of $D_{1}$ for Ding coal increased from 2.59 to 2.62 which while $D_{1}$ for Wu coal is reduced from 2.56 to 2.42. Considering the above observation, it can be concluded that the $D_{1}$ value is verily different in soft and hard coal. Ding seam showed a greater value of $D_{1}$ confirms the high adsorption capacity. Contrary, the value $D_{2}$ of coal Ding reduced from 2.37 to 2.20 between the samples, while Wu evident the same 
value of 2.39. According to the meaning of $D_{2}$, the smaller its value, the smaller the pore structure anisotropy leads to greater gas adsorption capacities are (Wang et al., 2019). It is confirmed from the above results that, Ding coal seam has a high adsorption capacity with a lower $D_{2}$ value. It is confirmed from the above analysis that the deterioration in the roughness of coal surface and reduction in anisotropy of the pore structure is mainly occurred by geological tectonic moments (Wang et al., 2019).

Correlation plots of PV and SSA of mesopores and micropores versus fractal dimensions are depicted in Fig. 9. It can be seen that the BJH-PV and BET-SSA of coals exhibit a positive correlation with $D_{1}$. The correlation coefficient $\left(\mathrm{R}^{2}\right)$ of BET-SSA and BJH-PV are 0.65 and 0.99 , respectively. The results indicate that BJH-PV has a good fitting relation than BET-SSA. However, there is negative relation with $D_{2}$, indicating that BET-SSA and BJH-PV decreased gradually with the increase of $\mathrm{D}_{2}$ value, as confirmed by a previous study (Wang et al., 2019). On the contrary, the SSA-DFT of micropores also shown a positive linear correlation with $D_{1}$ and a negative relation with $D_{2}$. On the other hand, DFT-PV has a polynomial correlation coefficient with $D_{1}$ and $D_{2}$. The obtained curves revealed that the rougher the pore surface of the particles is, the larger the PV and SSA are. The rough pore surface provides more adsorption sites for gas adsorption, resulting in stronger gas adsorption capacities (Y. Yao et al., 2008). It indicates that although the samples are taken from the same coal seam, the samples with different strengths show different fractural characteristics and adsorption properties. At the same time, $D_{1}$ of soft coal is more significant than that of hard coal, which is one of the reasons that the former's adsorption capacity is greater than that of the latter (Wang et al., 2019).

\subsection{Influence of Pore SSA and Pore Volume on Gas Adorability}

Gas adsorption in coal occurs in three steps: (1) gas molecules diffuse through the surface layer of coal, (2) gas molecules travel through internal pores, and (3) gas molecules are assembled by pore walls (W. Zhao et al., 2014). Therefore, the pore structure of the coal matrix has a significant influence on the adorability of gas (Lu and Cheng, 2015). In the adsorption state, CBM is retained on the inner surface of coal micropores and mesopores, so the SSA and PV of micropores and mesopores are of great significance to the adsorption capacity and gas accumulation. According to the basic physical adsorption theory on a solid surface, the adsorption capability of the object is in direct proportion to the SSA (Chen et al., 2017; Laxminarayana and Crosdale, 1999).

The BET surface area result of coals determined by the $\mathrm{N}_{2}$ adsorption experiment is presented in Fig. 5 . The BET-SSA decrease between four coal samples in the following order: DN56-2 > DN56-1 > WU9101,>WU910-2, showing consistency with the adsorption capacity $\left(V_{L}\right)$ of samples evaluated. The BET-SSA of the DN56-2 has an extremely high surface area compared with the other samples, which implies the higher adsorption capacity, based on the results of a previous study (Qi et al., 2017).

Figure 10a shows that BJH-PV and BET-SSA are linearly related to adsorption volume. The increase of SSA and PV of micropores and mesopores has an increasing influence on gas adsorption in the coal 
body. Therefore, SSA and PV of micropores and mesopores contribute to the gas adsorption capacity of the coal. By comparing BJH-PV and BET-SSA, BET-SSA has a good linear fitting with the adsorption volume, which indicates its influence on methane adsorption in coal is greater than BJH-PV. The BET-SSA of soft coal is higher than hard coal. The adsorption capacity of both coals increases with the increase in SSA of the pores, i.e., the increase of SSA promotes gas adsorption. Simultaneously, the influence of micropores on $\mathrm{V}_{\mathrm{L}}$ is greater than that of transition and mesopores, as evident by a study (Meng et al., 2015). SSA and PV of micropores show the same trend with adsorption volume. Figure $10 \mathrm{~b}$ depicts the relationship of SSA and PV of micropores obtained by the $\mathrm{CO}_{2}$ adsorption experiment. The results presented in Fig. 10a and Fig. 10b conclude that the adsorption capacity of coal seams is greatly influenced by specific surface areas of micro and meso pores. The influence is followed by DFT-PV and BJH-PV.

\section{Conclusions}

This study evaluated the pore structure and fractural characteristics of soft and hard coals with the same coalification. In order to clearly understand the evolution of CBM and the variance in outburst sensitivity of the coal seams, $\mathrm{N}_{2} / \mathrm{CO}_{2}$-adsorption tests were performed, and the following conclusions were drawn.

1. The physical parameters of coals are consistent. The firmness coefficient $(f)$ of coal reveals that hard coal has higher strength than soft coal. The vitrinite reflectance is in the range of $0.5 \%<\mathrm{Ro}$; max $>0.9 \%$, designating the coalification of coals as low volatile bituminous coal.

2. The adsorption isotherms of $\mathrm{N}_{2}$-adsorption at low temperature experiments are classified as type IV (A) and type II. The shape of hysteresis loops indicates numerous slit-shaped pores. $\mathrm{N}_{2}$-isotherms show that soft coal is mainly mesoporous and microporous, evidenced by the PSD, BET-SSA, and BJH-PV. Hard coal samples are mesoporous. For soft coal, SSA increases with the increase of destruction type, and BET-SSA among the coal samples increases in the order of DN56-2 > DN56-1 > WU910-1,>WU910-2, showing consistency with the adsorption capacity.

3. $\mathrm{CO}_{2}$ isotherms analyzed by the QSDFT model to obtain PSDs, PV, and SSA of micropores (super and ultra-micropores) concludes that the coal samples are mainly concentrated by ultra-micropores, and a large number of super-micropores also revealed. Like BET-SSA, the DFT-SSA of soft coal is higher than hard coal.

4. The fractural dimensions values $\left(D_{1}\right.$ and $\left.D_{2}\right)$ vary with coal strength. The $D_{1}$ of soft coal increased from 2.59 to 2.62 , while that for hard coal decreased from 2.56 to 2.42 . It leads to the conclusion that $D_{1}$ is different in both coals, and soft coal shows greater value, which confirms the high adsorption capacity. The value of $D_{2}$ between soft coal samples decreased from 2.37 to 2.20 , while that for hard coal remained the same, i.e., 2.39. Therefore, the smaller the $D_{2}$ value is, the smaller the pore structure anisotropy leads to greater gas adsorption capacities.

5. Detailed analysis of pore structure and fractural characteristics performed based on coal strength found that low strength coal (soft coal) dramatically influences the evolution of pore structure and adsorption capacity, which can be traced to the strong sensitivity of coal gas outbursts in the 
particular coal seam. Therefore, the current study can be extended to evaluate the effect of geological structure on pore structure. Additionally, the relationship between coal seam thickness and coal strength is also worth investigating.

\section{Declarations}

\section{Compliance with Ethical Standards}

\section{Conflict of interest}

The authors declare no potential conflicts of interest.

\section{Funding}

This research was supported by the National Natural Science Foundation of China (No. 51874294, No. 51974300 and No. 52034008), the Fundamental Research Funds for the Central Universities (No.2017XKZD01 and No.2020ZDPY0224), the Six Talent Peaks Project in Jiangsu Province (GDZB-027).

\section{References}

Amarasekera, G.; Scarlett, M. J.; Mainwaring, D.E., 1995. Micropore size distributions and specific interactions in coals. Fuel. Fuel 74 (1), 115- 118.

Barkat Ullah, Yuanping Cheng, Liang Wang, Biao Hu, Izhar Mithal Jiskani, Fawad Ul Hassan, Niaz Muhammad Shahani, M.A., 2021. Experimental and theoretical analyses to predict coal and gas outburst using desorption indices of drill cuttings. Arab. J. Geosci.

Barsotti, E., Tan, S.P., Saraji, S., Piri, M., Chen, J.-H., 2016a. A review on capillary condensation in nanoporous media: Implications for hydrocarbon recovery from tight reservoirs. Fuel 184, 344-361. https://doi.org/10.1016/j.fuel.2016.06.123

Barsotti, E., Tan, S.P., Saraji, S., Piri, M., Chen, J.H., 2016b. A review on capillary condensation in nanoporous media: Implications for hydrocarbon recovery from tight reservoirs. Fuel 184, 344-361. https://doi.org/10.1016/j.fuel.2016.06.123

C.R. Clarksona,*, R.M.B., 1999. The effect of pore structure and gas pressure upon the transport properties of coal: a laboratory and modeling study.1. Isotherms and pore volume distributions $78,1345-1362$.

Chen, K.P., 2011. A new mechanistic model for prediction of instantaneous coal outbursts - Dedicated to the memory of Prof. Daniel D. Joseph. Int. J. Coal Geol. https://doi.org/10.1016/j.coal.2011.04.012

Chen, S., Tao, S., Tang, D., Xu, H., Li, S., Zhao, J., Jiang, Q., Yang, H., 2017. Pore structure characterization of different rank coals using $\mathrm{N}_{2}$ and $\mathrm{CO}_{2}$ adsorption and its effect on $\mathrm{CH} 4$ adsorption capacity: A case in Panguan syncline, western Guizhou , China. 
Cheng, Y., Jiang, H., Zhang, X., Cui, J., Song, C., Li, X., 2017. Effects of coal rank on physicochemical properties of coal and on methane adsorption. Int. J. Coal Sci. Technol. 4, 129-146. https://doi.org/10.1007/s40789-017-0161-6

Cheng, Y.P., Wang, L., Zhang, X.L., 2011. Environmental impact of coal mine methane emissions and responding strategies in China. Int. J. Greenh. Gas Control. https://doi.org/10.1016/j.ijggc.2010.07.007

Clarkson, C.R., Bustin, R.M., 1999. The effect of pore structure and gas pressure upon the transport properties of coal: a laboratory and modeling study. 1. Isotherms and pore volume distributions. Fuel 78, 1333-1344. https://doi.org/10.1016/S0016-2361(99)00055-1

Clarkson, C. R., Bustin, R.M., 1999. Effect of pore structure and gas pressure upon the transport properties of coal: a laboratory and modeling study. 2. Adsorption rate modeling. Fuel 78, 1345-1362. https://doi.org/10.1016/S0016-2361(99)00056-3

Clarkson, C.R., Solano, N., Bustin, R.M., Bustin, A.M.M., Chalmers, G.R.L., He, L., Melnichenko, Y.B., Radliński, A.P., Blach, T.P., 2013. Pore structure characterization of North American shale gas reservoirs using USANS/SANS, gas adsorption, and mercury intrusion. Fuel 103, 606-616. https://doi.org/10.1016/j.fuel.2012.06.119

Fu, H., Tang, D., Xu, T., Xu, H., Tao, S., Li, S., Yin, Z.Y., Chen, B., Zhang, C., Fu, H., Tang, D., Xu, H., Tao, S., Li, S., Yin, Z.Y., Chen, B., Zhang, C., Wang, L., 2017a. Characteristics of pore structure and fractal dimension of low-rank coal: A case study of Lower Jurassic Xishanyao coal in the southern Junggar Basin, NW China. Fuel 193, 254-264. https://doi.org/10.1016/j.fuel.2016.11.069

Fu, H., Tang, D., Xu, T., Xu, H., Tao, S., Li, S., Yin, Z.Y., Chen, B., Zhang, C., Fu, H., Tang, D., Xu, H., Tao, S., Li, S., Yin, Z.Y., Chen, B., Zhang, C., Wang, L., 2017b. Characteristics of pore structure and fractal dimension of low-rank coal: A case study of Lower Jurassic Xishanyao coal in the southern Junggar Basin, NW China. Fuel 193, 254-264. https://doi.org/10.1016/j.fuel.2016.11.069

Guo, H., Cheng, Y., Yuan, L., Wang, L., Zhou, H., 2016. Unsteady-State Diffusion of Gas in Coals and Its Relationship with Coal Pore Structure. Energy and Fuels 30, 7014-7024.

https://doi.org/10.1021/acs.energyfuels.6b01218

Hou, S., Wang, Xiaoming, Wang, Xingjin, Yuan, Y., Pan, S., Wang, Xiaomei, 2017. Pore structure characterization of low volatile bituminous coals with different particle size and tectonic deformation using low pressure gas adsorption. Int. J. Coal Geol. https://doi.org/10.1016/j.coal.2017.09.013

Jiang, J., Yang, W., Cheng, Y., Zhao, K., Zheng, S., 2019a. Pore structure characterization of coal particles via MIP, N2 and CO2 adsorption: Effect of coalification on nanopores evolution. Powder Technol. 354, 136-148. https://doi.org/10.1016/j.powtec.2019.05.080 
Jiang, J., Yang, W., Cheng, Y., Zhao, K., Zheng, S., 2019b. Pore structure characterization of coal particles via MIP, N2 and CO2 adsorption: Effect of coalification on nanopores evolution. Powder Technol. 354, 136-148. https://doi.org/10.1016/j.powtec.2019.05.080

Jin, K., Cheng, Y., Liu, Q., Zhao, W., Wang, L., Wang, F., 2016. Experimental Investigation of Pore Structure Damage in Pulverized Coal: Implications for Methane Adsorption and Di ff usion Characteristics. https://doi.org/10.1021/acs.energyfuels.6b02530

Laxminarayana, C., Crosdale, P.J., 1999. Role of coal type and rank on methane sorption characteristics of Bowen Basin, Australia coals. Int. J. Coal Geol. 40, 309-325. https://doi.org/10.1016/S01665162(99)00005-1

Li, J., Liu, D., Yao, Y., Cai, Y., Xu, L., Huang, S., 2014. Control of CO2 permeability change in different rank coals during pressure depletion: An experimental study. Energy and Fuels.

https://doi.org/10.1021/ef402285n

Li, X., Jiang, C., Tang, J., Chen, Y., Yang, D., Chen, Z., 2017. A Fisher's Criterion-Based Linear Discriminant Analysis for Predicting the Critical Values of Coal and Gas Outbursts Using the Initial Gas Flow in a Borehole. Math. Probl. Eng. https://doi.org/10.1155/2017/7189803

Lu, S., Cheng, Y., 2015. Pore structure and its impact on $\mathrm{CH} 4$ adsorption capability and diffusion characteristics of normal and deformed coals from Qinshui Basin Liang Wang 10, 94-114.

Meng, Z.P., Liu, S.S., Wang, B.Y., Tian, Y.D., Wu, J., 2015. Adsorption capacity and its pore structure of coals with different coal body structure. Meitan Xuebao/Journal China Coal Soc.

https://doi.org/10.13225/j.cnki.jccs.2015.0620

Neimark, A. V.; Lin, Y.; Ravikovitch, P. I.; Thommes, M., 2009. Quenched solid density functional theory and pore size analysis of micro-mesoporous carbons. Carbon N. Y. 47(7), 1617-1628.

Nie, B., Liu, X., Yang, L., Meng, J., Li, X., 2015. Pore structure characterization of different rank coals using gas adsorption and scanning electron microscopy. Fuel 158, 908-917.

https://doi.org/10.1016/j.fuel.2015.06.050

Qi, L., Tang, X., Wang, Z., Peng, X., 2017. Pore characterization of different types of coal from coal and gas outburst disaster sites using low temperature nitrogen adsorption approach. Int. J. Min. Sci. Technol. 27, 371-377. https://doi.org/10.1016/j.ijmst.2017.01.005

Ren, P., Xu, H., Tang, D., Li, Y., Chen, Z., Sun, C., Zhang, F., Chen, S., Xin, F., Cao, L., 2019a. Pore structure and fractal characterization of main coal-bearing synclines in western Guizhou, China. J. Nat. Gas Sci. Eng. 63, 58-69. https://doi.org/10.1016/j.jngse.2019.01.010

Ren, P., Xu, H., Tang, D., Li, Y., Chen, Z., Sun, C., Zhang, F., Chen, S., Xin, F., Cao, L., 2019b. Pore structure and fractal characterization of main coal-bearing synclines in western Guizhou, China. J. Nat. Gas Sci. 
Eng. 63, 58-69. https://doi.org/10.1016/j.jngse.2019.01.010

Shi, J.-Q., Durucan, S., 2005. Gas Storage and Flow in Coalbed Reservoirs: Implementation of a Bidisperse Pore Model for Gas Diffusion in Coal Matrix. SPE Reserv. Eval. Eng. 8, 169-175.

https://doi.org/10.2118/84342-PA

Shi, J.Q., Durucan, S., 2003. Gas Storage and Flow in Coalbed Reservoirs: Implementation of a Bidisperse Pore Model for Gas Diffusion in Coal Matrix, in: Proceedings - SPE Annual Technical Conference and Exhibition. https://doi.org/10.2523/84342-ms

Sun, W., Feng, Y., Jiang, C., Chu, W., 2015. Fractal characterization and methane adsorption features of coal particles taken from shallow and deep coalmine layers. Fuel.

https://doi.org/10.1016/j.fuel.2015.03.083

Sun, Z., Li, L., Wang, F., Zhou, G., 2020. Desorption characterization of soft and hard coal and its influence on outburst prediction index. Energy Sources, Part A Recover. Util. Environ. Eff. 42, 2807-2821.

https://doi.org/10.1080/15567036.2019.1618991

Tang, Y.Y., Sun, S.Q., Tian, G.L., 2005. Study of computer identifying on tectonic soft coal with well log. Meitan Xuebao/Journal China Coal Soc.

Thommes, M., Kaneko, K., Neimark, A. V., Olivier, J.P., Rodriguez-Reinoso, F., Rouquerol, J., Sing, K.S.W., 2015. Physisorption of gases, with special reference to the evaluation of surface area and pore size distribution (IUPAC Technical Report). Pure Appl. Chem. 87, 1051-1069. https://doi.org/10.1515/pac2014-1117

Wang, C., Yang, S., Jiang, C., Yang, D., Zhang, C., Li, X., Chen, Y., Tang, J., 2017. A method of rapid determination of gas pressure in a coal seam based on the advantages of gas spherical flow field. J. Nat. Gas Sci. Eng. https://doi.org/10.1016/j.jngse.2017.05.021

Wang, L., Liu, S., Cheng, Y.P., Yin, G. zhi, Guo, P. kun, Mou, J. hui, 2017. The effects of magma intrusion on localized stress distribution and its implications for coal mine outburst hazards. Eng. Geol. https://doi.org/10.1016/j.enggeo.2017.01.002

Wang, S., Elsworth, D., Liu, J., 2013. Mechanical behavior of methane infiltrated coal: The roles of gas desorption, stress level and loading rate. Rock Mech. Rock Eng. https://doi.org/10.1007/s00603-0120324-0

Wang, Z., Cheng, Y., Qi, Y., Wang, R., Wang, L., Jiang, J., 2019. Experimental study of pore structure and fractal characteristics of pulverized intact coal and tectonic coal by low temperature nitrogen adsorption. Powder Technol. https://doi.org/10.1016/j.powtec.2019.03.030

Wang, Z., Cheng, Y., Zhang, K., Hao, C., Wang, L., Li, W., Hu, B., 2018. Characteristics of microscopic pore structure and fractal dimension of bituminous coal by cyclic gas adsorption/desorption: An experimental 
study. Fuel 232, 495-505. https://doi.org/10.1016/j.fuel.2018.06.004

Wei, P., Liang, Y., Zhao, S., Peng, S., Li, X., Meng, R., 2019. Characterization of pores and fractures in soft coal from the No. 5 soft coalbed in the Chenghe Mining Area. Processes 7, 1-19. https://doi.org/10.3390/pr7010013

Wu, F.A.Y.C.D., Wang, L., 2013. The effect of small micropores on methane adsorption of coals from Northern China 83-90. https://doi.org/10.1007/s10450-012-9421-3

Xue, S., Yuan, L., Wang, Y., Xie, J., 2014. Numerical analyses of the major parameters affecting the initiation of outbursts of coal and gas. Rock Mech. Rock Eng. https://doi.org/10.1007/s00603-013-04254

Y. Yao, D. Liu, D. Tang, S. Tang, W.H., 2008. Fractal characterization of adsorptionpores of coals from North China: An investigation on CH adsorption capacity of coals. Int. J. Coal Geol 73, 27-42.

Yao, Y., Liu, D., Che, Y., Tang, D., Tang, S., Huang, W., 2010. Petrophysical characterization of coals by lowfield nuclear magnetic resonance (NMR). Fuel 89, 1371-1380. https://doi.org/10.1016/j.fuel.2009.11.005

Yao, Y., Liu, D., Tang, D., Tang, S., Che, Y., Huang, W., 2009a. Preliminary evaluation of the coalbed methane production potential and its geological controls in the Weibei Coalfield, Southeastern Ordos Basin, China. Int. J. Coal Geol. https://doi.org/10.1016/j.coal.2008.09.011

Yao, Y., Liu, D., Tang, D., Tang, S., Che, Y., Huang, W., 2009b. International Journal of Coal Geology Preliminary evaluation of the coalbed methane production potential and its geological controls in the Weibei Coal fi eld, Southeastern Ordos Basin , China. Int. J. Coal Geol. 78, 1-15. https://doi.org/10.1016/j.coal.2008.09.011

Yao, Y., Liu, D., Tang, D., Tang, S., Huang, W., 2008. Fractal characterization of adsorption-pores of coals from North China: An investigation on $\mathrm{CH} 4$ adsorption capacity of coals. Int. J. Coal Geol. 73, 27-42. https://doi.org/10.1016/j.coal.2007.07.003

Yin, G., Shang, D., Li, M., Huang, J., Gong, T., Song, Z., 2018. Permeability evolution and mesoscopic cracking behaviors of liquid nitrogen cryogenic freeze fracturing in low permeable and heterogeneous coal. Powder Technol. 325, 234-246. https://doi.org/10.1016/j.powtec.2017.10.058

Yue, J., Wang, Z., Chen, J., 2019a. Dynamic response characteristics of water and methane during isobaric imbibition process in remolded coal containing methane. Energy Explor. Exploit. https://doi.org/10.1177/0144598718798083

Yue, J., Wang, Z., Chen, J., Zheng, M., Wang, Q., Lou, X., 2019b. Investigation of pore structure characteristics and adsorption characteristics of coals with different destruction types. Adsorpt. Sci. Technol. 37, 623-648. https://doi.org/10.1177/0263617419868076 
Zarebska, K., Ceglarska-Stefańska, G., 2008. The change in effective stress associated with swelling during carbon dioxide sequestration on natural gas recovery. Int. J. Coal Geol. https://doi.org/10.1016/j.coal.2007.11.003

Zhang, D., Gu, L., Li, S., Lian, P., Tao, J., 2013. Interactions of Supercritical CO 2 with Coal. Energy \& Fuels 27, 387-393. https://doi.org/10.1021/ef301191p

Zhang, K., Cheng, Y., Jin, K., Guo, H., Liu, Q., Dong, J., Li, W., 2017. Effects of Supercritical CO2 Fluids on Pore Morphology of Coal: Implications for CO2 Geological Sequestration. Energy and Fuels 31, 47314741. https://doi.org/10.1021/acs.energyfuels.6b03225

Zhao, J., Xu, H., Tang, D., Mathews, J.P., Li, S., Tao, S., 2016. A comparative evaluation of coal specific surface area by $\mathrm{CO} 2$ and $\mathrm{N} 2$ adsorption and its influence on $\mathrm{CH} 4$ adsorption capacity at different pore sizes. Fuel 183, 420-431. https://doi.org/10.1016/j.fuel.2016.06.076

Zhao, W., Cheng, Y., Yuan, M., An, F., 2014. Effect of adsorption contact time on coking coal particle desorption characteristics. Energy and Fuels 28, 2287-2296. https://doi.org/10.1021/ef402093g

Zhao, Y., Liu, S., Elsworth, D., Jiang, Y., Zhu, J., 2014. Pore structure characterization of coal by synchrotron small-angle X-ray scattering and transmission electron microscopy. Energy and Fuels 28, 3704-3711. https://doi.org/10.1021/ef500487d

\section{Figures}




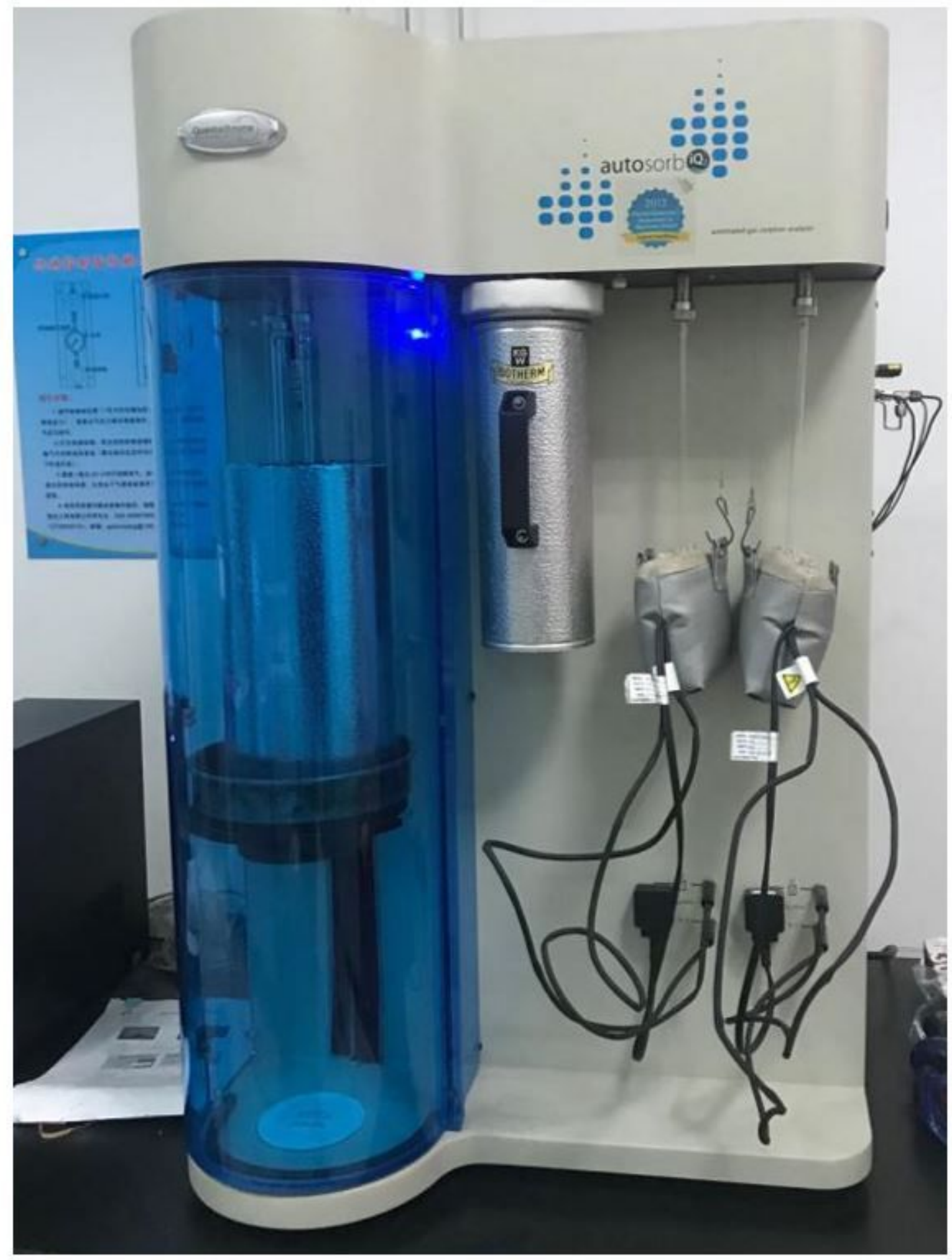

Figure 1

Quanta chrome instrument. 


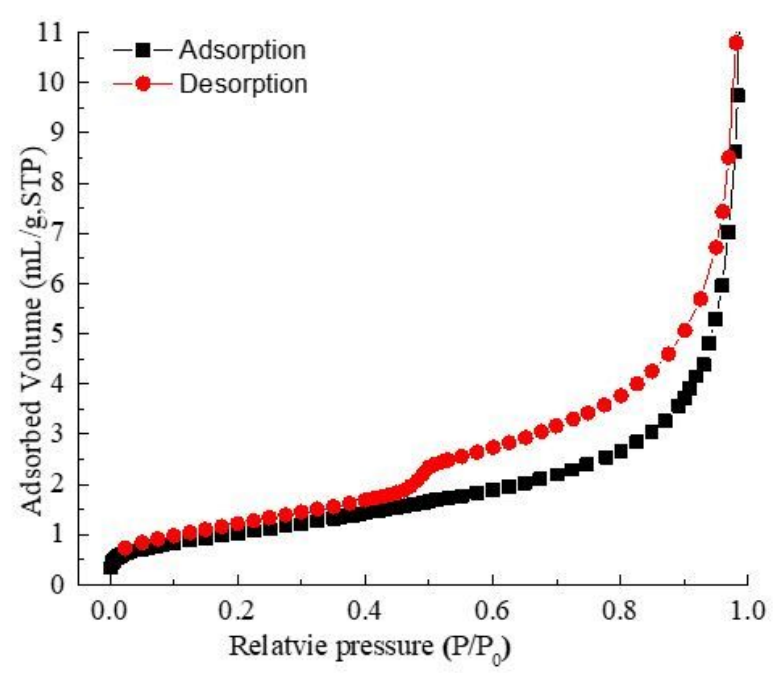

(A) DN56-1

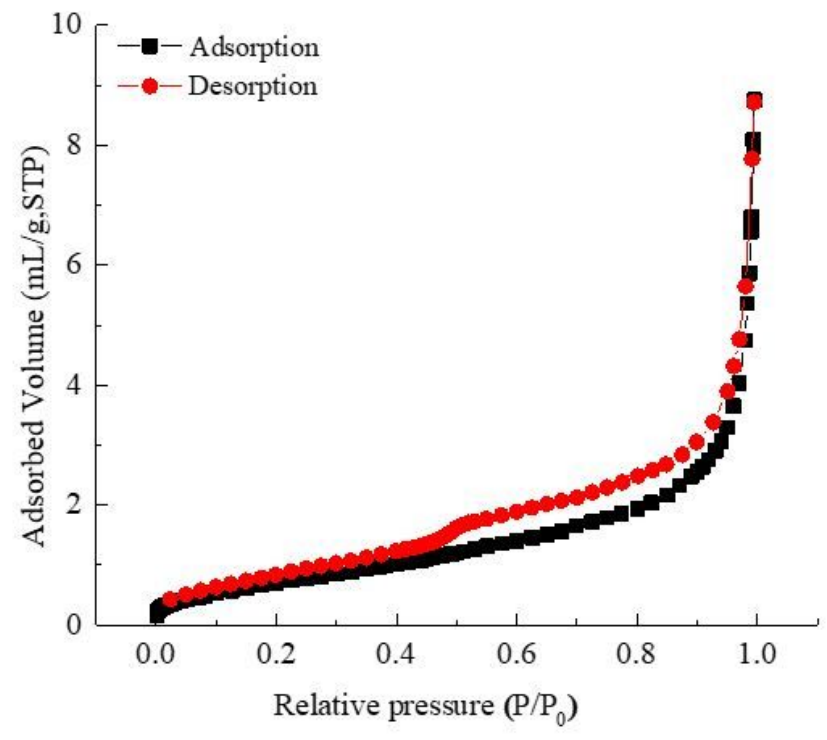

(C) WU910-1

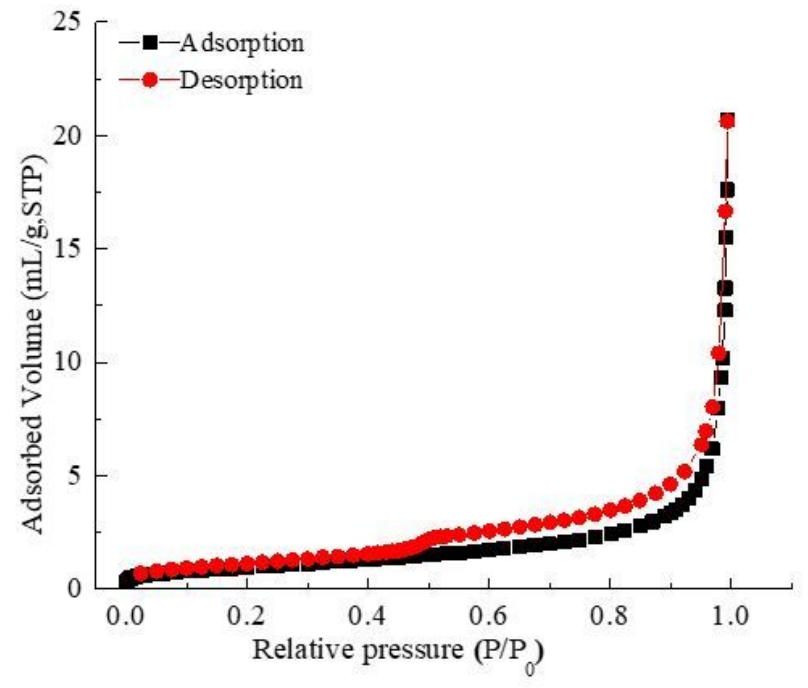

(B) DN56-2

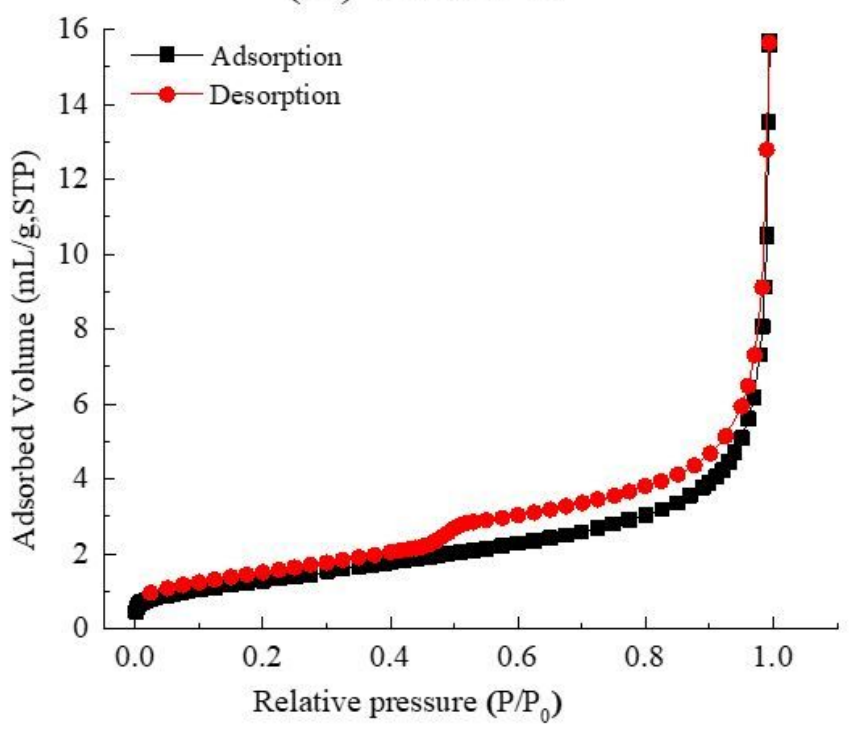

(D) WU910-2

Figure 2

Adsorption isotherms obtained by N2-adsorption. 

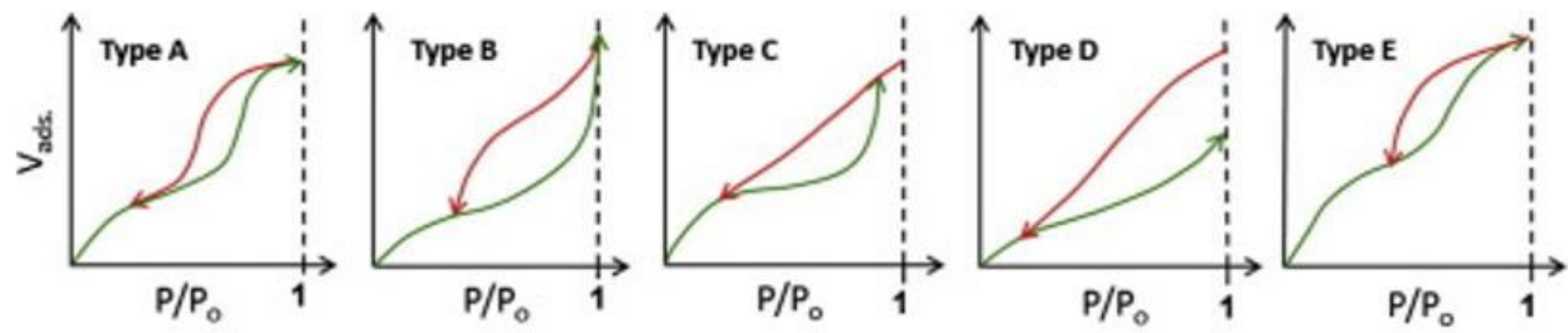

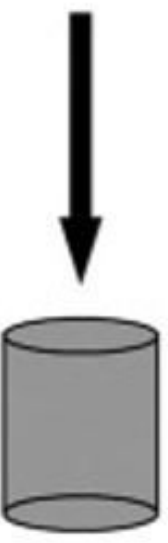

Cylindrical
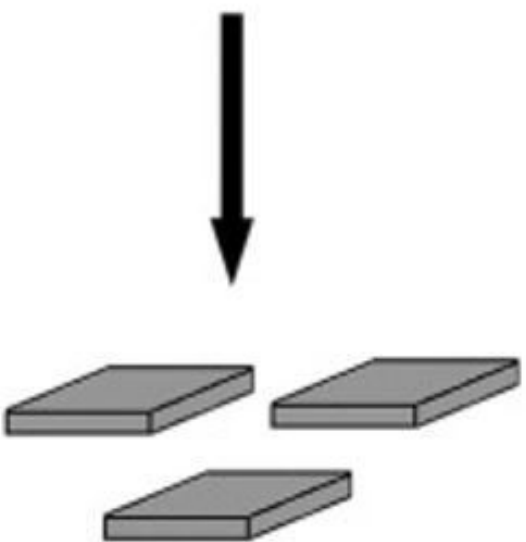

Slits
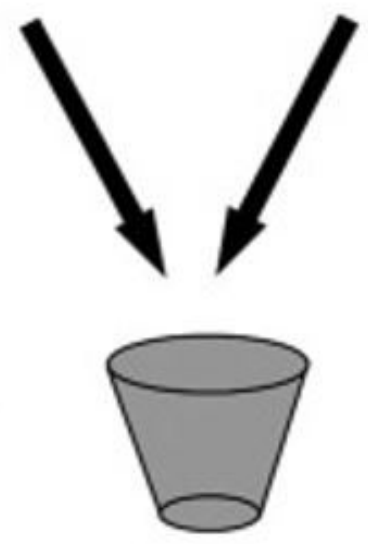

Wedge shaped

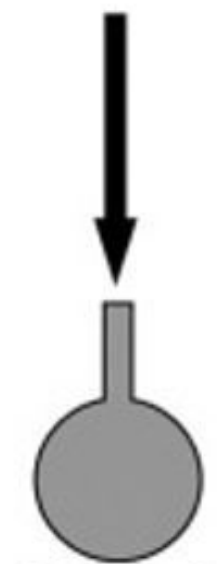

Bottle neck

\section{Figure 3}

Hysteresis loops and their corresponding pore shapes (Guo et al., 2016; Nie et al., 2015).

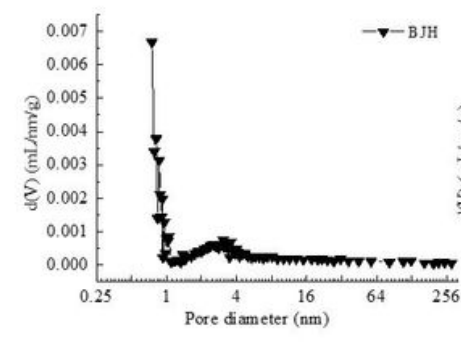

(A)

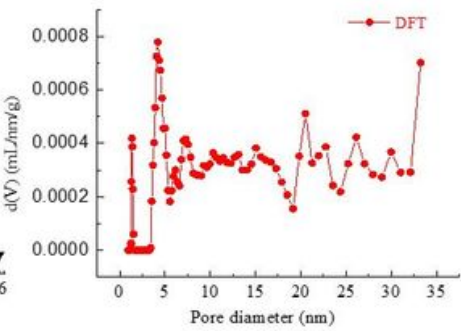

DN56-1

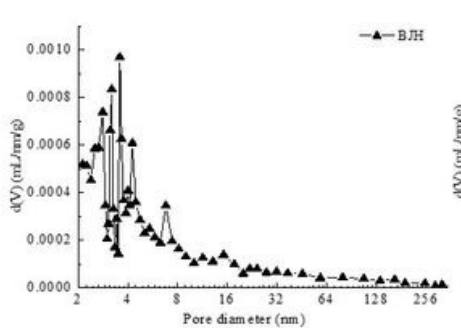

(C)

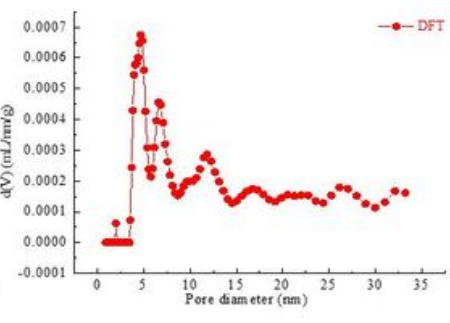

WU910-1

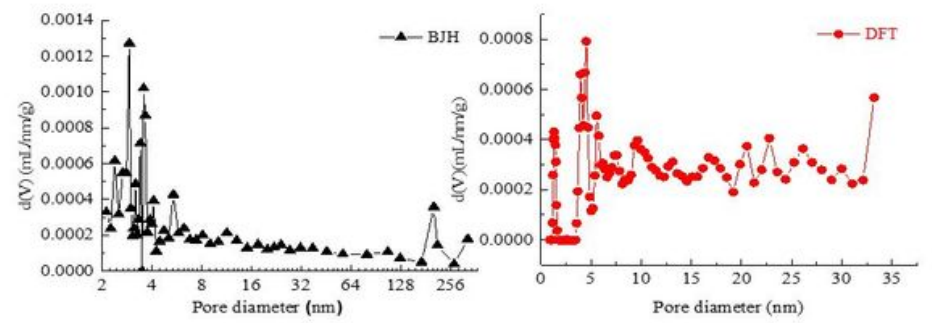

(B)

DN56-2
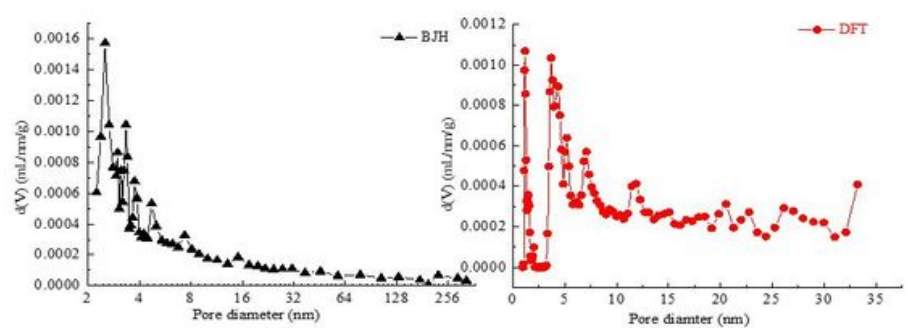

(D)

WU910-2

Figure 4 
Pore size distribution of coal determined by BJH and DFT Model.

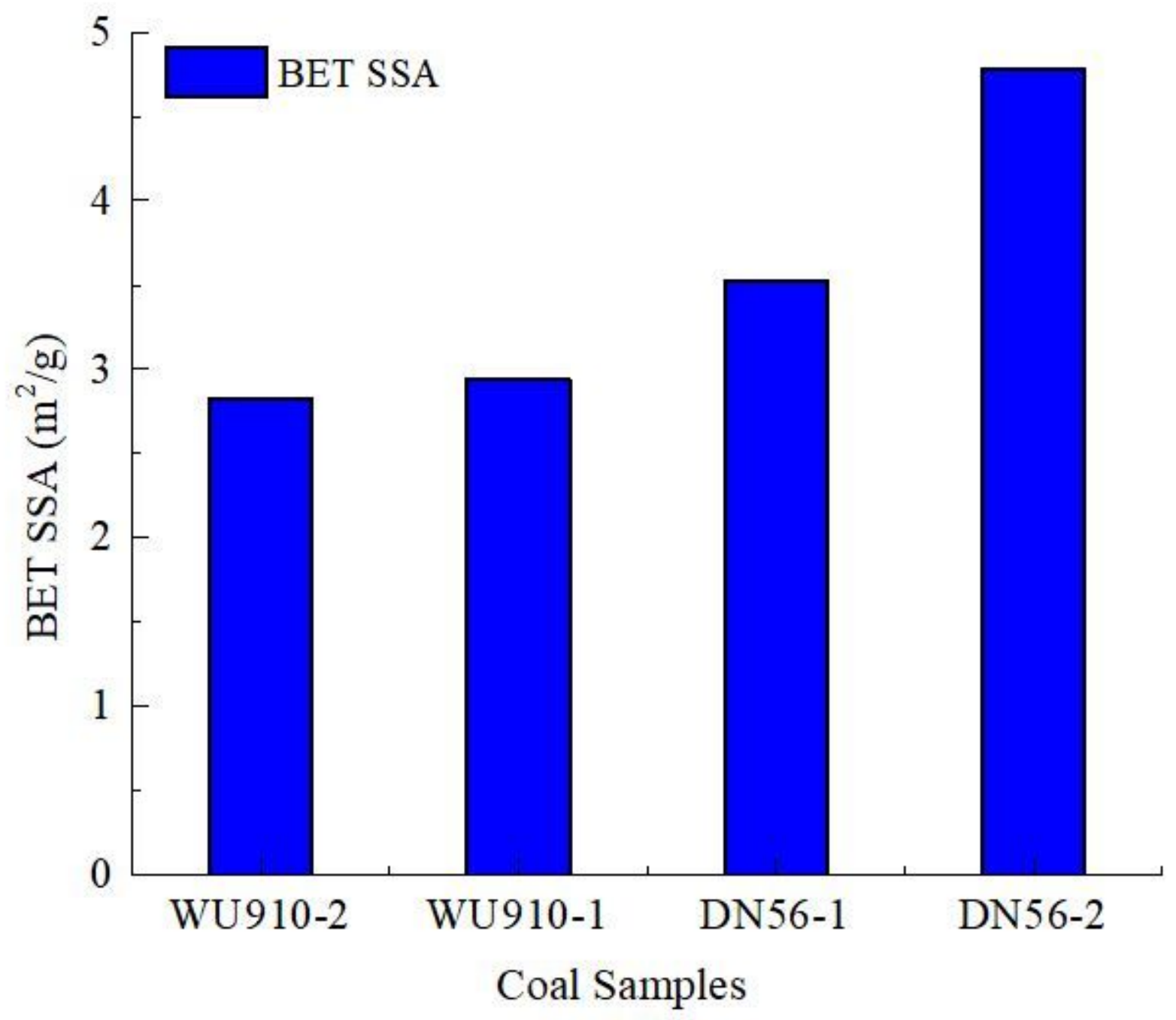

Figure 5

BET SSA comparison with samples from Ding5-6 and Wu9-10 coal seams. 


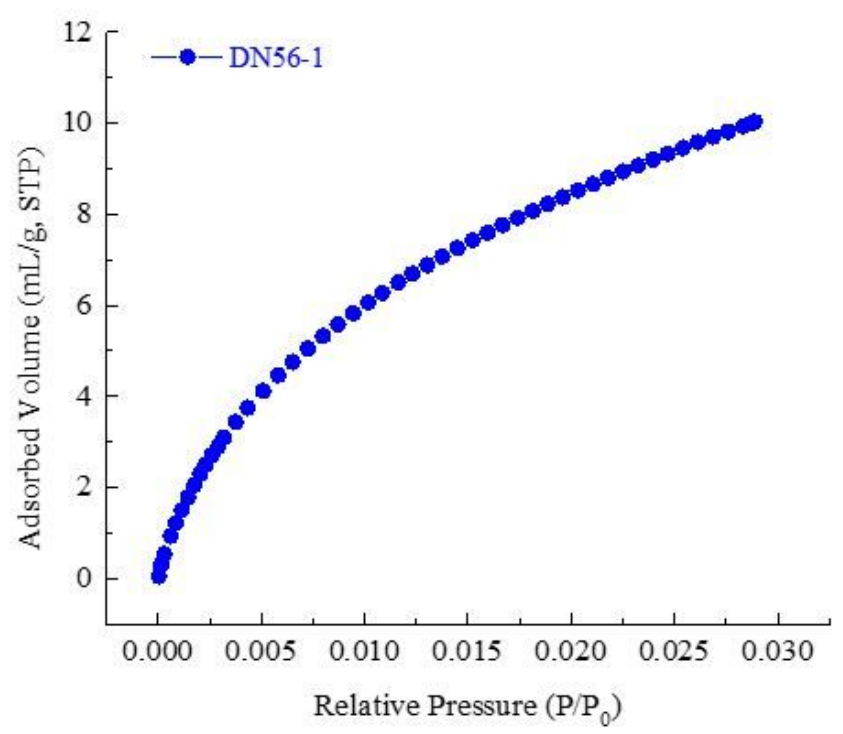

(A)

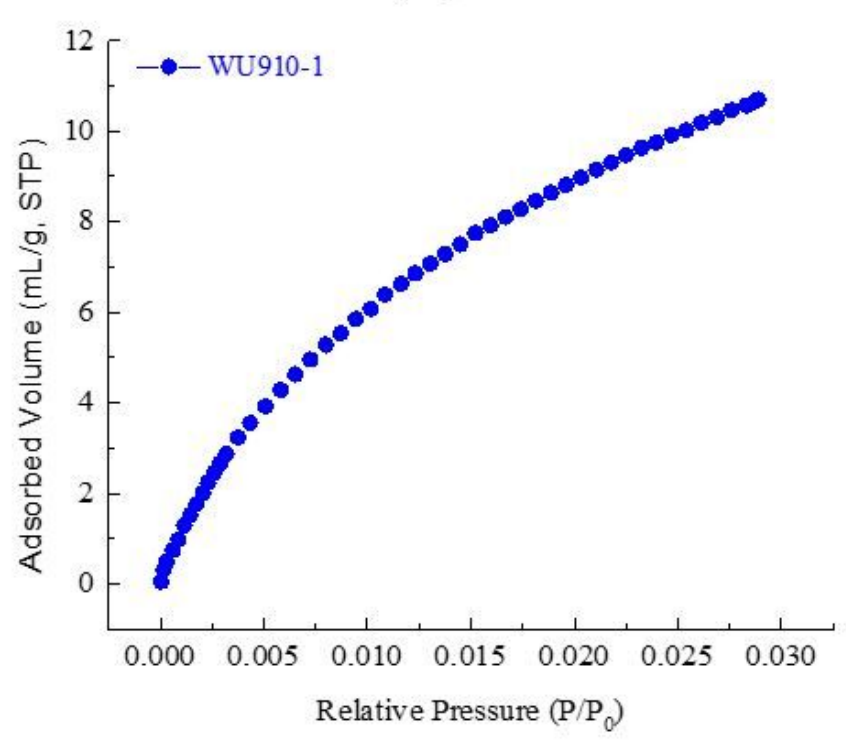

(C)

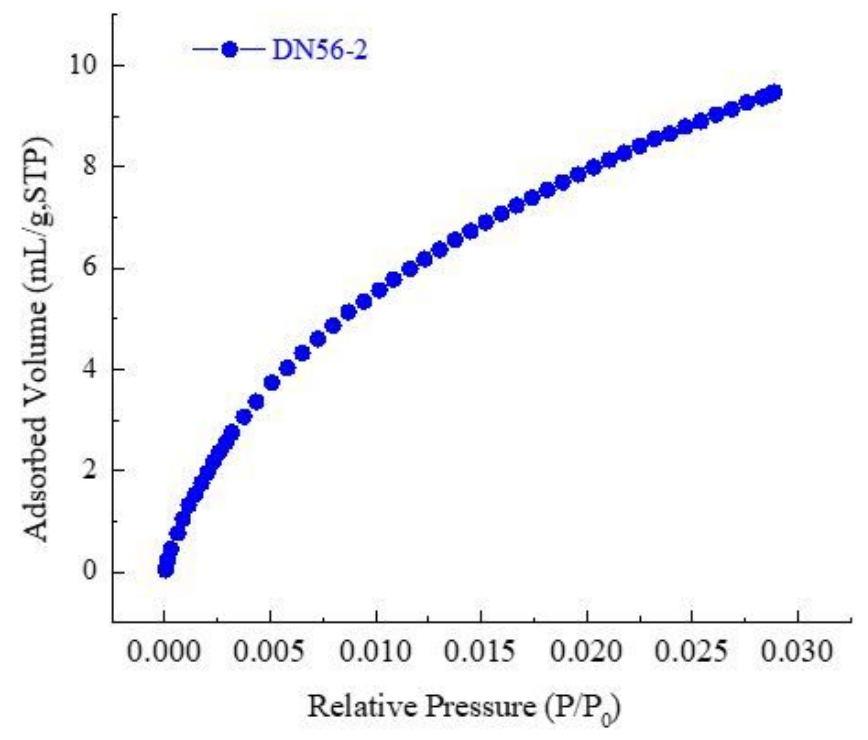

(B)

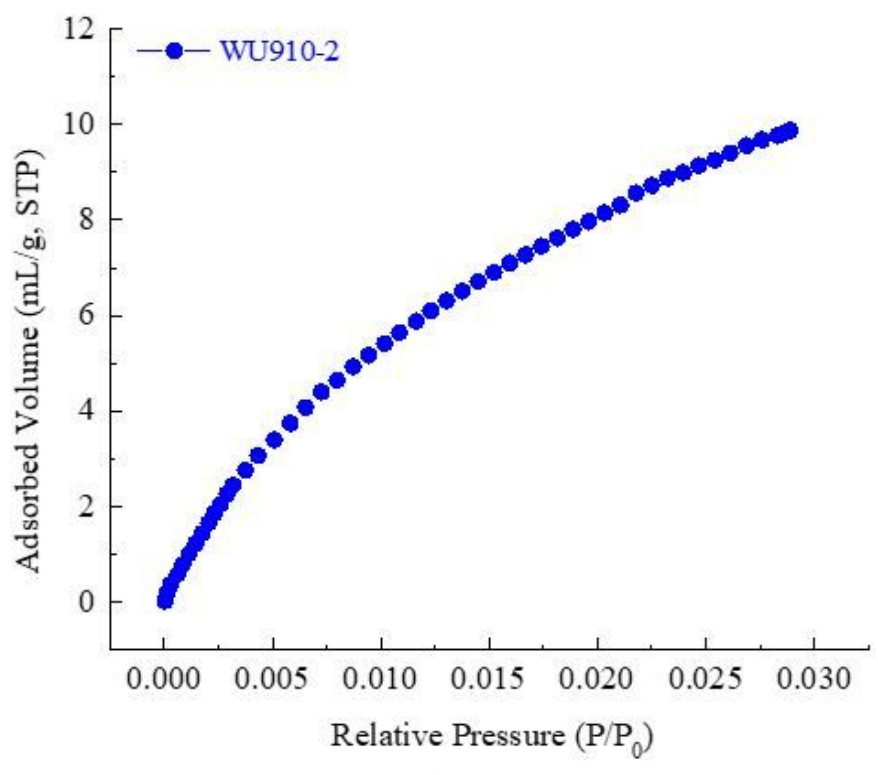

(D)

Figure 6

CO2 adsorption isotherms 


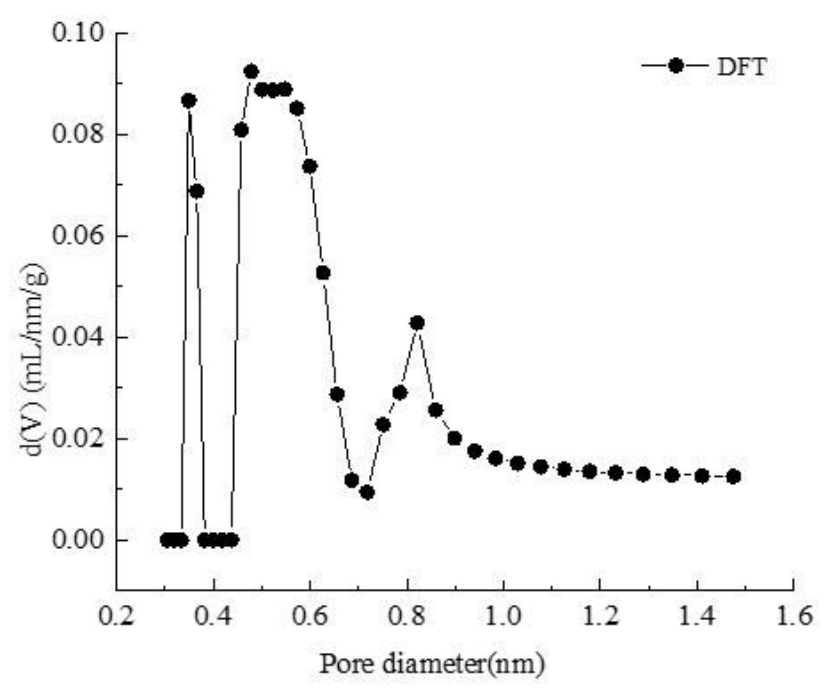

(A) DN56-1

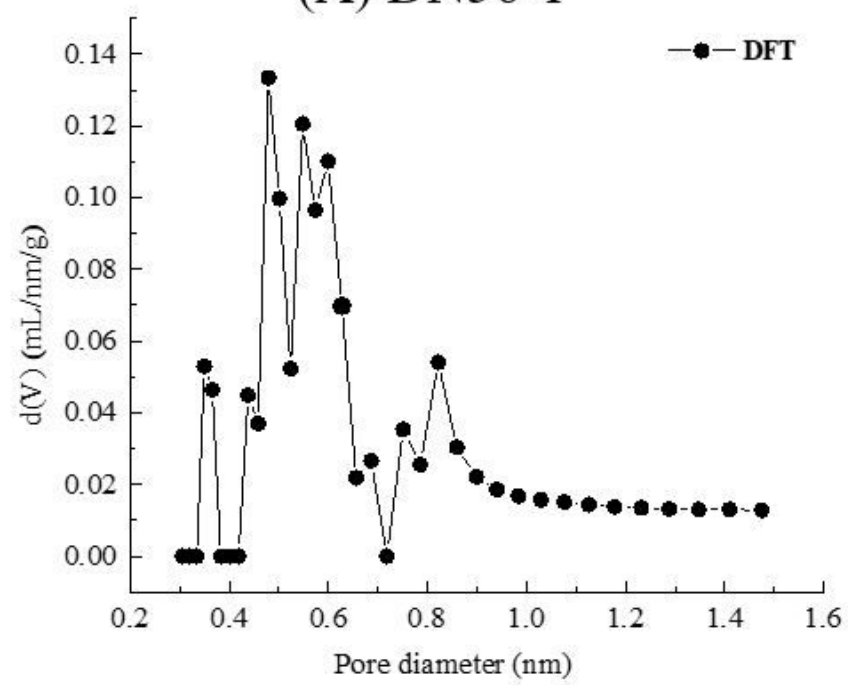

(C) WU910-1

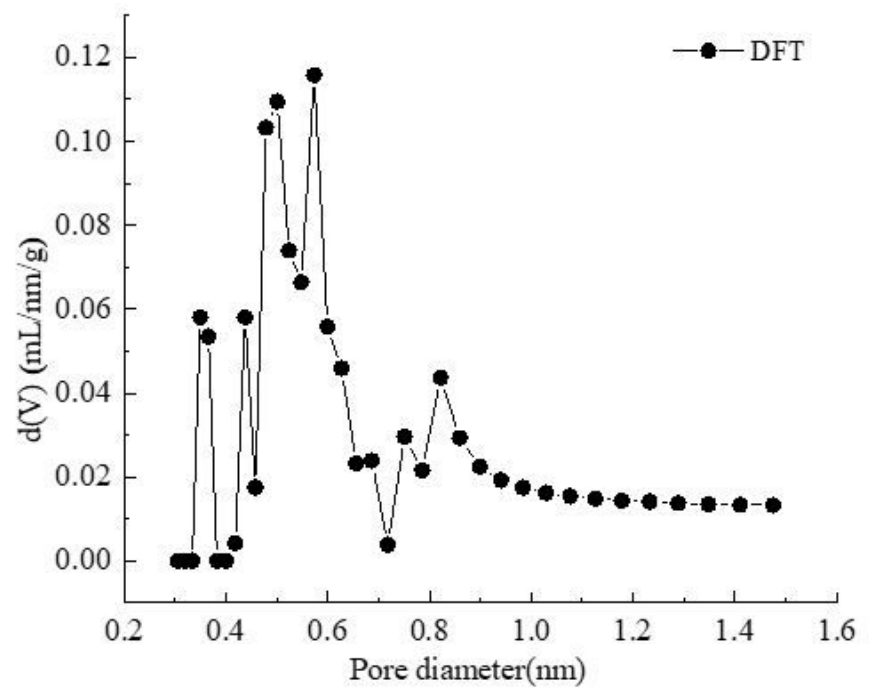

(B) DN56-2

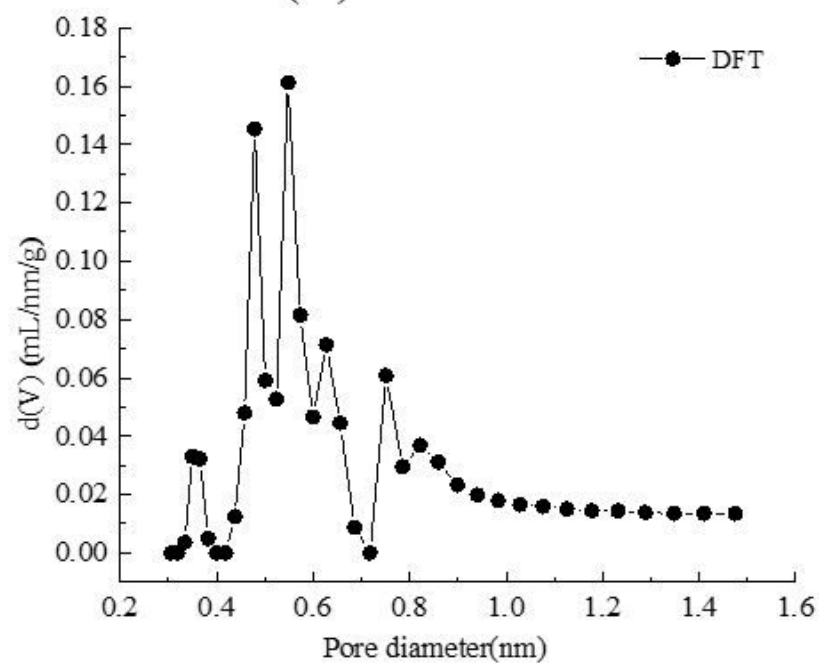

(D) WU910-2

Figure 7

Pore size distributions by CO2-adsorption 


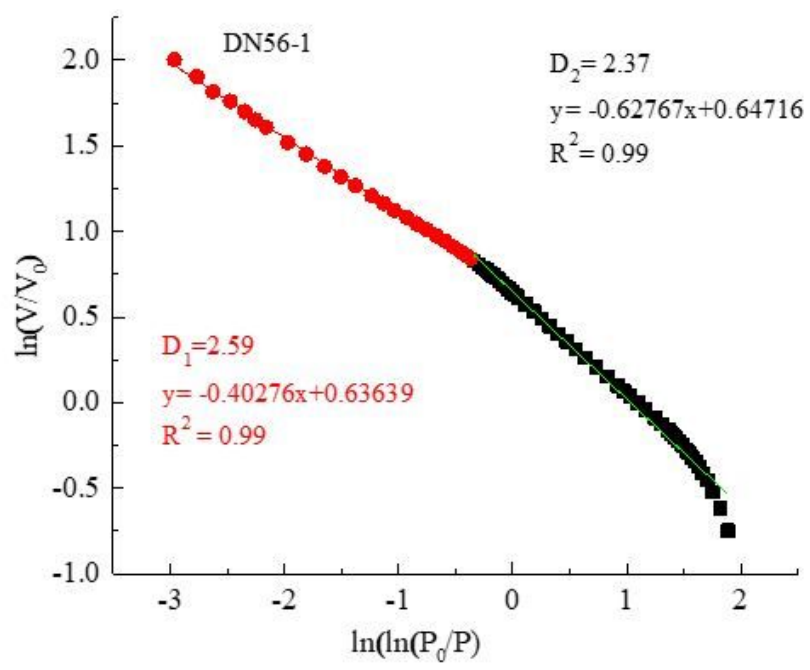

(A)

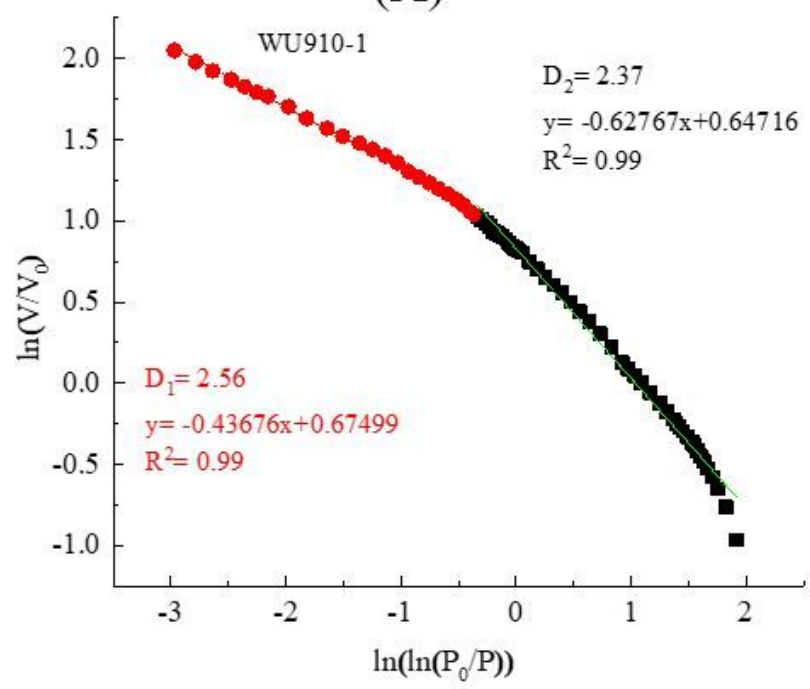

(C)

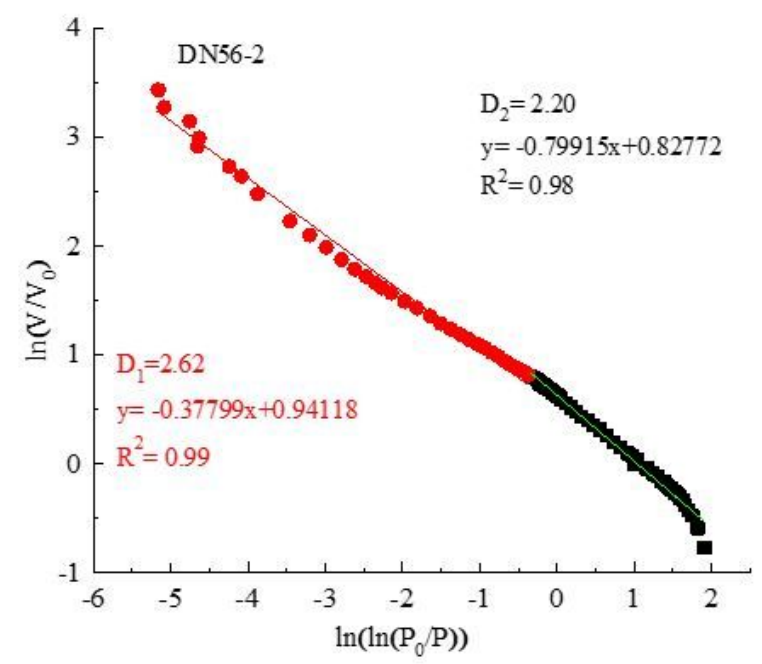

(B)

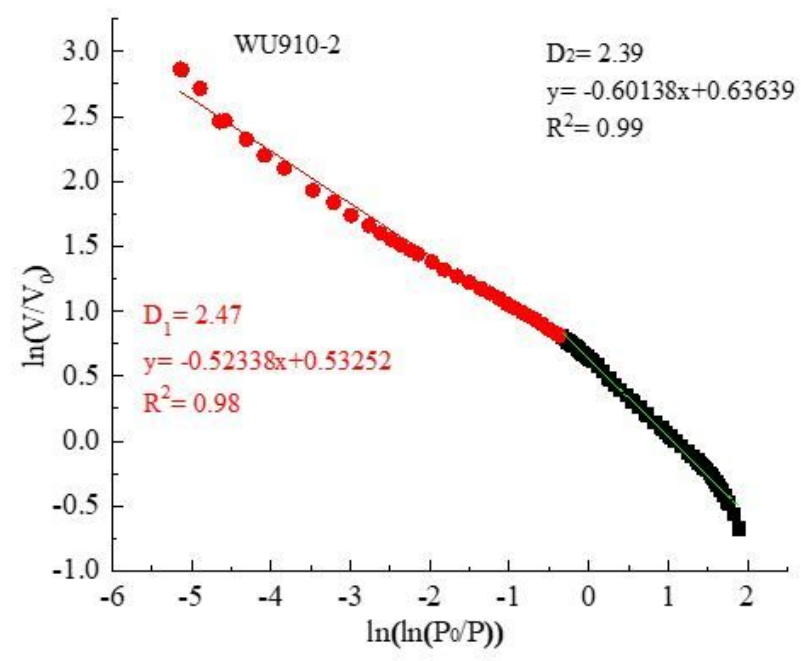

(D)

Figure 8

Fractural characterization determined by N2-adsorption experiment 

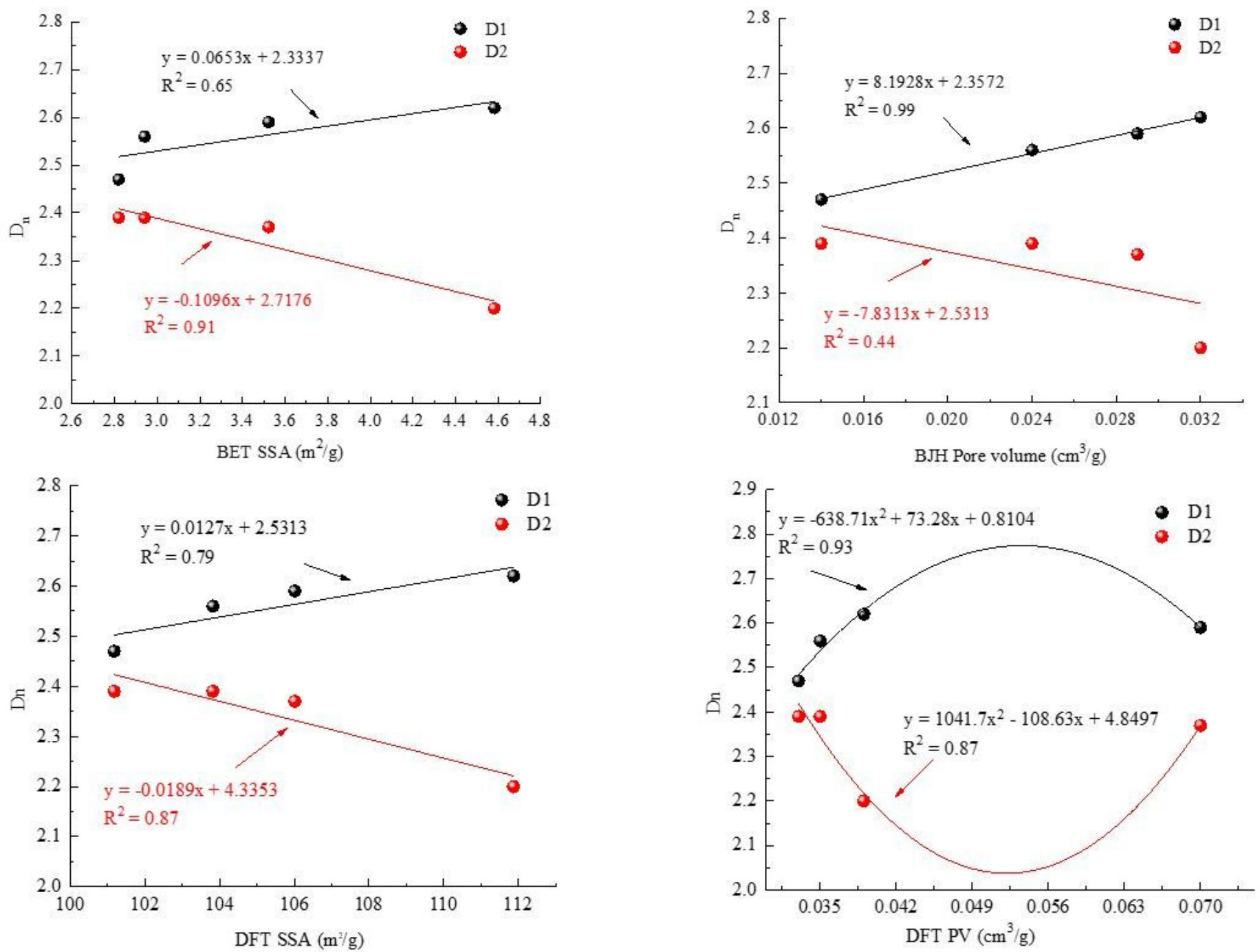

Figure 9

Relation of adsorption volume with BET-SSA, BJH pore volume, DFT-SSA, and DFT pore volume versus fractural dimensions. 


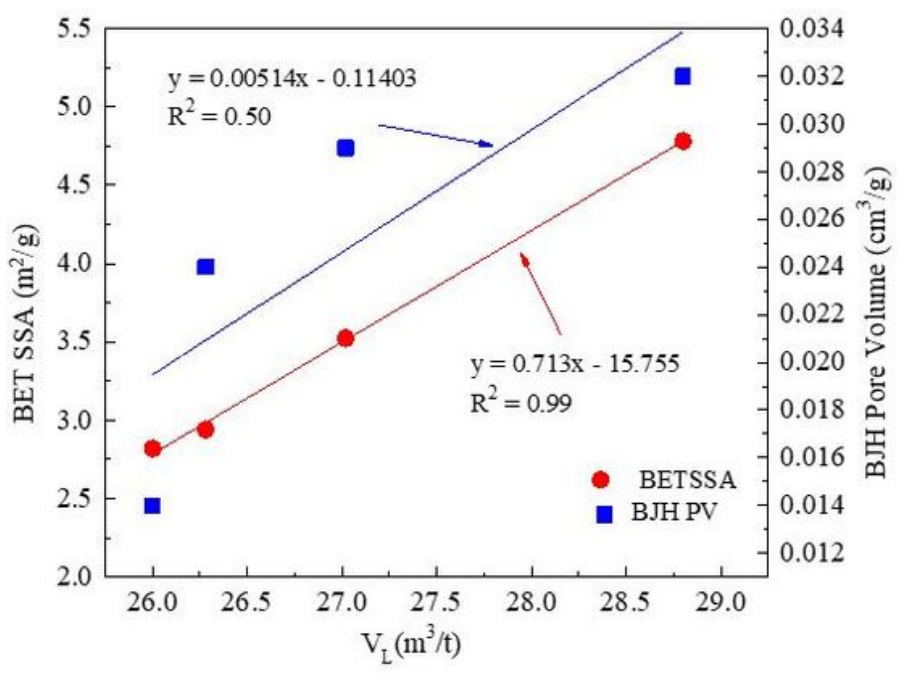

(A)

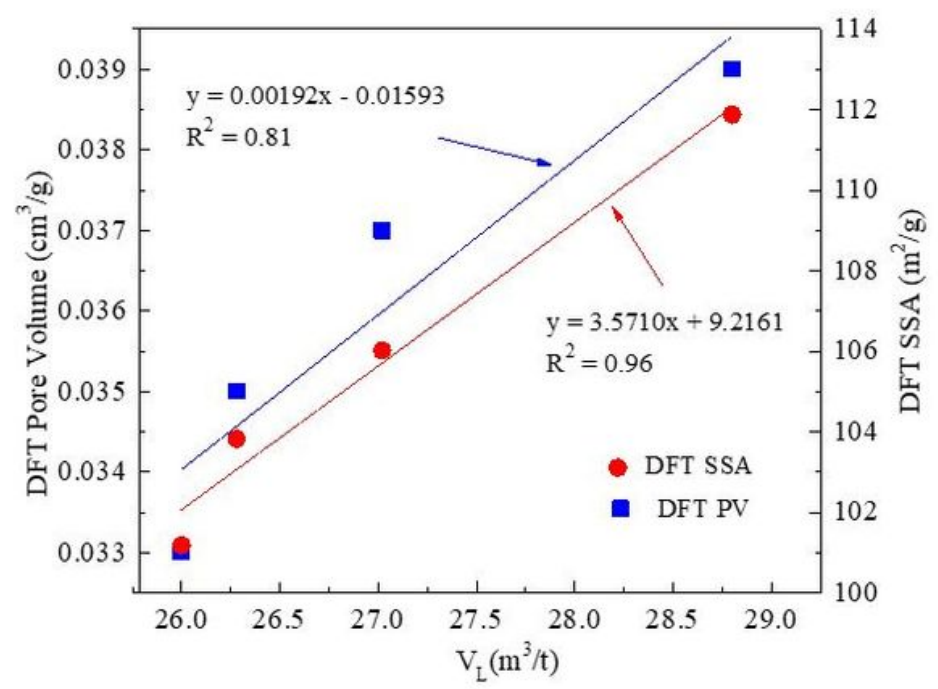

(B)

Figure 10

Relation of adsorption volume (VL) with BET-SSA, BJH-PV, DFT-SSA and DFT-PV 